\title{
SCIENTIFIC REP RTS \\ Author Correction: Carboxythiazole is a key microbial nutrient currency and critical component of thiamin biosynthesis
}

Ryan W. Paerl $\mathbb{D D}^{1,2}$, Erin M. Bertrand $\mathbb{D}^{3}{ }^{3}$, Elden Rowland ${ }^{3}$, Phillippe Schatt ${ }^{4}$, Mohamed Mehiri ${ }^{5}$ Thomas D. Niehaus ${ }^{6}$, Andrew D. Hanson ${ }^{6}$, Lasse Riemann $\mathbb{1}^{2}$ \& Francois-Yves Bouget ${ }^{5}$

Correction to: Scientific Reports https://doi.org/10.1038/s41598-018-24321-2, published online 13 April 2018

The original version of this Article contained a typographical error in the spelling of the author Francois-Yves Bouget, which was incorrectly given as Francois Yves-Bouget. This has now been corrected in the PDF and HTML versions of the Article and in the accompanying Supplementary Information file.

(i) Open Access This article is licensed under a Creative Commons Attribution 4.0 International License, which permits use, sharing, adaptation, distribution and reproduction in any medium or format, as long as you give appropriate credit to the original author(s) and the source, provide a link to the Creative Commons license, and indicate if changes were made. The images or other third party material in this article are included in the article's Creative Commons license, unless indicated otherwise in a credit line to the material. If material is not included in the article's Creative Commons license and your intended use is not permitted by statutory regulation or exceeds the permitted use, you will need to obtain permission directly from the copyright holder. To view a copy of this license, visit http://creativecommons.org/licenses/by/4.0/.

(c) The Author(s) 2018

${ }^{1}$ Department of Marine Earth and Atmospheric Sciences, North Carolina State University, Raleigh, NC, USA 27695, USA. ${ }^{2}$ Department of Biology, University of Copenhagen, 3000, Helsingør, Denmark. ${ }^{3}$ Department of Biology, Dalhousie University, Halifax, NS, Canada. ${ }^{4}$ Sorbonne Universités, Université Pierre and Marie Curie (Paris 06), UMR 7621, Laboratoire d'Océanographie Microbienne, Observatoire Océanologique, F-66650, Banyuls/mer, France. ${ }^{5}$ University Nice Côte d'Azur, CNRS, Institute of Chemistry of Nice, UMR 7272, Marine Natural Products Team, Nice, France. ${ }^{6}$ Horticultural Sciences Department, University of Florida, Gainesville, FL, USA 32611, USA. Correspondence and requests for materials should be addressed to R.W.P. (email: rpaerl@ncsu.edu) 